\title{
Barium titanate nanoparticles and hypergravity stimulation improve differentiation of mesenchymal stem cells into osteoblasts
}

This article was published in the following Dove Press journal:

International Journal of Nanomedicine

8 January 2015

Number of times this article has been viewed

\author{
Antonella Rocca ${ }^{1,2}$ \\ Attilio Marino ${ }^{1,2}$ \\ Veronica Rocca ${ }^{3}$ \\ Stefania Moscato ${ }^{4}$ \\ Giuseppe de Vito 5,6 \\ Vincenzo Piazza ${ }^{5}$ \\ Barbara Mazzolai ${ }^{1}$ \\ Virgilio Mattoli' \\ Thu Jennifer Ngo-Anh ${ }^{7}$ \\ Gianni Ciofani' \\ 'Istituto Italiano di Tecnologia, \\ Center for Micro-BioRobotics @ \\ SSSA, Pontedera, Italy, ${ }^{2}$ Scuola \\ Superiore Sant'Anna, The BioRobotics \\ Institute, Pontedera, Italy, ${ }^{3}$ Università \\ di Pisa, Dipartimento di Ingegneria \\ dell'Informazione, Pisa, Italy, \\ ${ }^{4}$ Università di Pisa, Dipartimento di \\ Medicina Clinica e Sperimentale, Pisa, \\ Italy, ${ }^{5}$ Istituto Italiano di Tecnologia, \\ Center for Nanotechnology \\ Innovation @NEST, Pisa, Italy, ${ }^{6}$ Scuola \\ Normale Superiore, NEST, Pisa, Italy, \\ ${ }^{7}$ Directorate of Human Spaceflight \\ and Operations, European Space \\ Agency, Noordwijk, the Netherlands
}

Correspondence: Antonella Rocca/ Gianni Ciofani

Center for Micro-BioRobotics, Istituto Italiano di Tecnologia (IIT@SSSA),

34 Viale Rinaldo Piaggio, Pontedera,

Pisa 56025, Italy

Tel +39050883089

Fax +39050883497

Email antonella.rocca@iit.it/

gianni.ciofani@iit.it
Background: Enhancement of the osteogenic potential of mesenchymal stem cells (MSCs) is highly desirable in the field of bone regeneration. This paper proposes a new approach for the improvement of osteogenesis combining hypergravity with osteoinductive nanoparticles (NPs).

Materials and methods: In this study, we aimed to investigate the combined effects of hypergravity and barium titanate NPs (BTNPs) on the osteogenic differentiation of rat MSCs, and the hypergravity effects on NP internalization. To obtain the hypergravity condition, we used a large-diameter centrifuge in the presence of a BTNP-doped culture medium. We analyzed cell morphology and NP internalization with immunofluorescent staining and coherent anti-Stokes Raman scattering, respectively. Moreover, cell differentiation was evaluated both at the gene level with quantitative real-time reverse-transcription polymerase chain reaction and at the protein level with Western blotting.

Results: Following a $20 \mathrm{~g}$ treatment, we found alterations in cytoskeleton conformation, cellular shape and morphology, as well as a significant increment of expression of osteoblastic markers both at the gene and protein levels, jointly pointing to a substantial increment of NP uptake. Taken together, our findings suggest a synergistic effect of hypergravity and BTNPs in the enhancement of the osteogenic differentiation of MSCs.

Conclusion: The obtained results could become useful in the design of new approaches in bone-tissue engineering, as well as for in vitro drug-delivery strategies where an increment of nanocarrier internalization could result in a higher drug uptake by cell and/or tissue constructs. Keywords: mesenchymal stem cells, hypergravity, barium titanate nanoparticles, osteogenesis

\section{Introduction}

Physical stimuli can significantly alter cellular behavior, giving rise to biochemical signals involved in molecular response. ${ }^{1}$ This process is called mechanotransduction, and the responsible structures sensitive to mechanical forces are most probably cytoskeleton elements. ${ }^{2}$

A number of studies have demonstrated that cells are sensitive to several kinds of physical cues (shear stress, topography, mechanical deformation, etc), influencing cell migration, ${ }^{3}$ differentiation, ${ }^{4}$ and proliferation. ${ }^{5}$ Among these stimuli, gravity is required for the correct development of land-based organisms, and in particular for the skeleton and for the muscle and nervous systems. ${ }^{6}$

An increasing amount of research is focused on the effects of gravity alterations on the physiological processes, but also on the possibility to exploit this stimulus as a potential therapeutic cue. ${ }^{7-9}$ As an example, improved regeneration of infarcted myocardium has been achieved after injection of stem cells differentiated following 
a $2 g$ hypergravity treatment, which enhanced the activities of cardiac marker MEF-2 by promoting the nuclear export of histone deacetylase $5 .{ }^{10}$ Chang et al investigated altered gravity effects on human lung adenocarcinoma, demonstrating the ability of simulated microgravity to decrease the metastatic potential of this tumor cell line. ${ }^{11}$ Other researchers used microgravity stimulation as an approach for the development of a large amount of $\beta$-cell spheroids, which once transplanted in mice are able to improve the symptoms of diabetes. ${ }^{12}$

Among different tissues, bone is particularly affected by altered gravity conditions: evidence regarding bone regeneration suggests that hypergravity exposure - conversely to microgravity, which negatively affects osteogenesis - may enhance the osteogenic potential of osteoblast precursors. ${ }^{13}$ The ability of mesenchymal stem cells (MSCs) to differentiate into osteoblasts is well known, but the osteogenic potential of MSCs decreases with the prolonged culture duration necessary to obtain an appropriate number of cells for clinical applications. ${ }^{14}$ Some countermeasures to this issue could come from nanotechnology, which proposes many different typologies of nanoparticles (NPs) for stem cell labeling, tracking, delivery, and stimulation, ${ }^{15}$ including several examples of nanomaterials able to foster osteogenesis in MSCs. ${ }^{16-18}$

Our group, as an example, successfully exploited barium titanate NPs (BTNPs; Figure 1A) as a possible agent for the improvement of osteogenic differentiation of MSCs. ${ }^{19}$ BTNPs belong to a class of ferroelectric materials showing high piezoelectricity, ${ }^{20}$ and with regard to biomedical applications, they demonstrate high cytocompatibility, ${ }^{21}$ excellent properties as nonlinear imaging probes, ${ }^{22}$ and the ability to deliver doxorubicin in cancer cells by improving
A

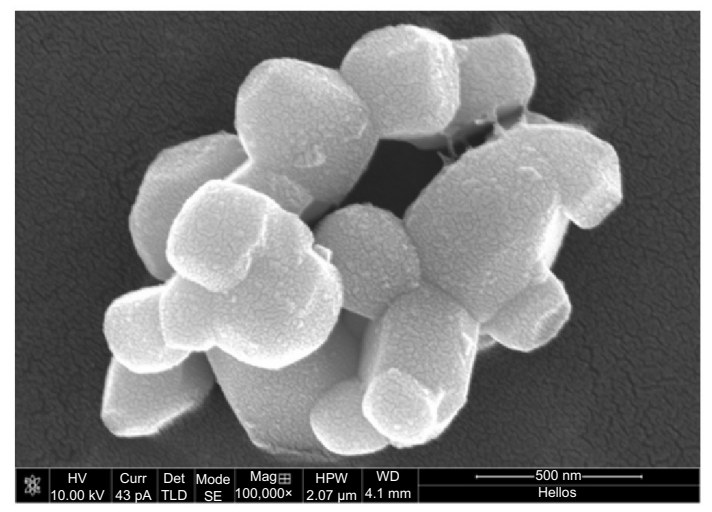

D

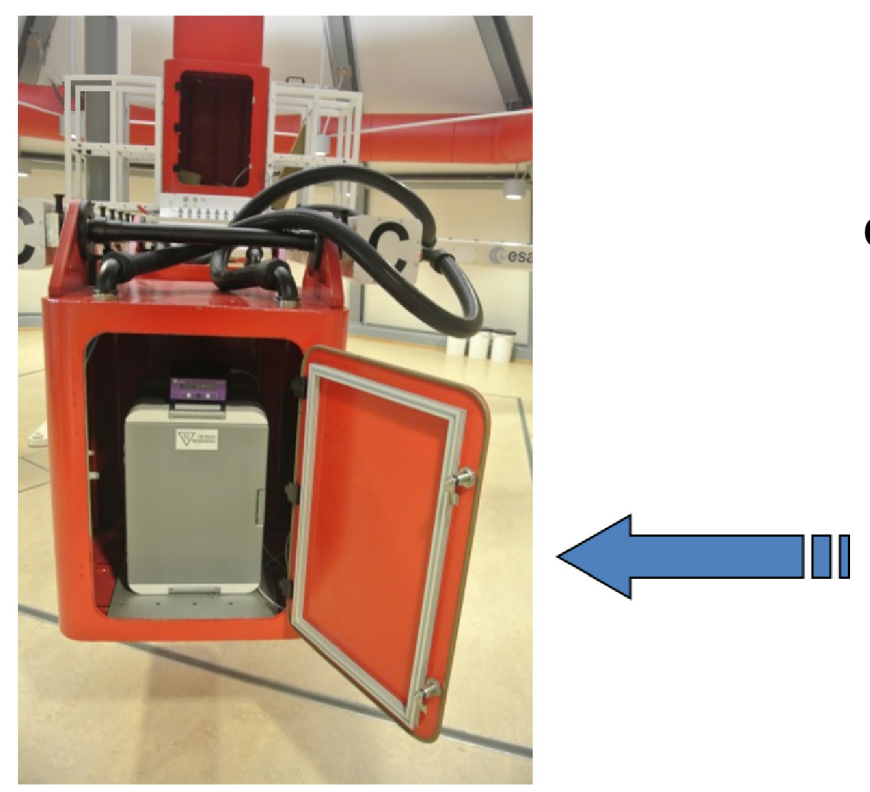

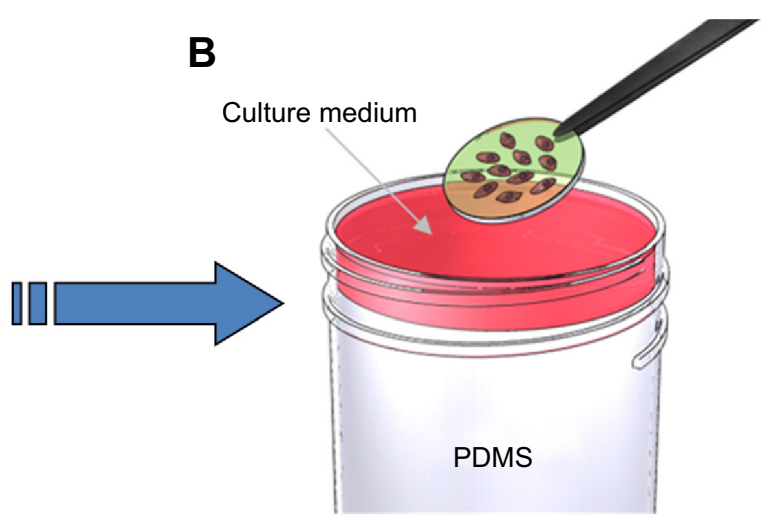

C
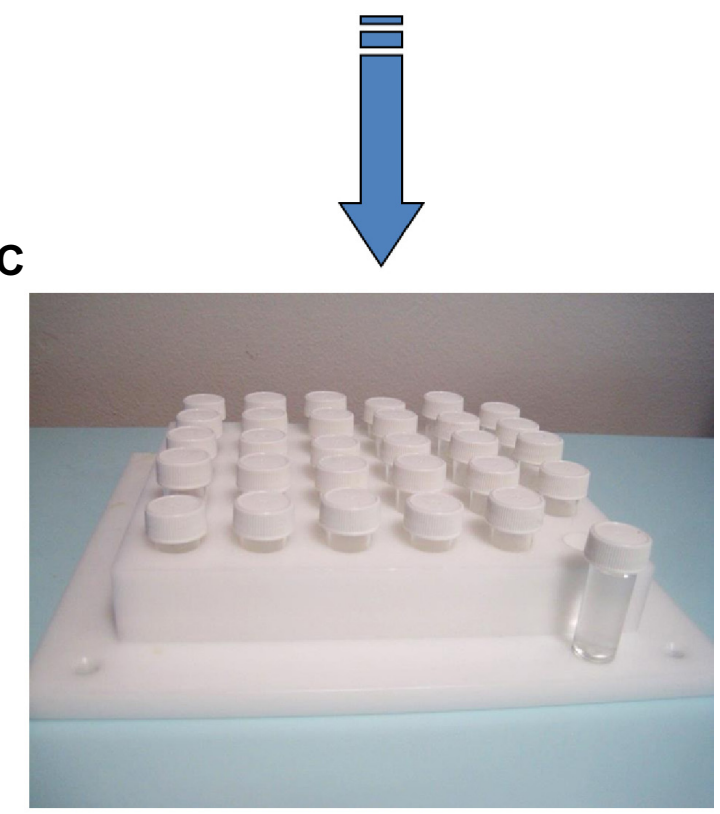

Figure I Barium titanate nanoparticles (BTNPs) and experimental setup.

Notes: Scanning electron microscopy image of BTNPs (A). Glass slides on which cells were cultured were transferred to cylindrical vials and covered with appropriate cellculture medium (B). Delrin structure designed to support 30 cylindrical vials (C). The structure with the samples was inserted in the swinging gondola of the large-diameter centrifuge. The centrifuge system is composed of four large rotating arms with a gondola at each extremity, and allowed the achievement of the hypergravity condition (D). Abbreviation: PDMS, polydimethylsiloxane. 
drug uptake. ${ }^{23}$ Moreover, as previously mentioned, BTNPs were proven to enhance the osteogenesis of MSCs, as demonstrated by an increment of hydroxyapatite deposition.

Starting from these findings, we decided to develop a protocol for MSC stimulation by combining incubation with BTNPs with treatment in hypergravity, with the goal of improving the differentiation process toward osteoblasts, and thus to obtain stem cells with enhanced osteogenic differentiation potential. Experiments were performed within the framework of the "Spin Your Thesis! 2013" campaign at the European Space Agency (ESA; Noordwijk, the Netherlands), taking advantage of the large-diameter centrifuge for the hypergravity treatment.

With the proposed experimental protocol, we had the aims of 1) investigating cell morphology and differentiation (at gene, protein, and phenotype level) following the combination of hypergravity treatment and BTNP administration, and 2) evaluating NP uptake by stem cells in altered gravity conditions, thus investigating the possibility of enhancing cellular internalization by simply exploiting an increased gravitational force.

\section{Materials and methods}

\section{Cell culture and experimental procedures in the large-diameter centrifuge}

Rat MSCs (SCR027; Millipore) were used at the second passage in all the experiments. For the maintenance of MSCs, the medium was composed of Dulbecco's Modified Eagle's Medium supplemented with 10\% fetal bovine serum, $100 \mathrm{U} / \mathrm{mL}$ penicillin, $100 \mathrm{mg} / \mathrm{mL}$ streptomycin, and $200 \mathrm{mM}$ glutamine (all these reagents from Gibco). Cultures were maintained in an incubator at standard culture conditions $\left(37^{\circ} \mathrm{C}, 5 \% \mathrm{CO}_{2}\right.$, and $100 \%$ humidity).

For all the experiments, MSCs were trypsinized and seeded on glass slides (diameter $13 \mathrm{~mm}$ ) 48 hours before hypergravity treatment at $10,000 / \mathrm{cm}^{2}$ for tests in proliferation conditions and at $30,000 / \mathrm{cm}^{2}$ for tests under osteogenic differentiation. Osteogenesis was induced in the differentiation samples immediately before the hypergravity treatment by supplementing the medium with $100 \mathrm{nM}$ dexamethasone, 200 $\mu \mathrm{M}$ ascorbic acid 2-phosphate, and $10 \mathrm{mM}$ glycerol 2-phosphate (all these reagents from Sigma-Aldrich). Differentiating conditions were maintained throughout the hypergravity treatment and during poststimulation incubation.

Some samples (both proliferating and differentiating) were moreover provided with BTNPs $(20 \mu \mathrm{g} / \mathrm{mL})$, also in this case immediately before the hypergravity treatment. This dose was selected based on our previous results of an analysis of BTNP effects on MSCs, where $20 \mu \mathrm{g} / \mathrm{mL}$ was found to be the optimal concentration at which NPs did not negatively affect cellular functions. ${ }^{19}$ The NPs, obtained from Nanostructured and Amorphous Materials (Houston, TX, USA), were about $150 \mathrm{~nm}$ in radius, and were administered to the cell culture upon stabilization in gum Arabic (Sigma-Aldrich). Images of the final dispersion of BTNPs were acquired after gold-sputtering by scanning electron microscopy through a dual-beam system (FEI Helios 600; Figure 1A). Further details on NP characterization have been previously reported. ${ }^{19}$

Glass slides supporting the cell cultures were transferred in cylindrical vials filled with biocompatible polydimethylsiloxane (10:1 base:cross-linking agent ratio, curing temperature $60^{\circ} \mathrm{C}$ ), and fully covered with $800 \mu \mathrm{L}$ of the appropriate cell-culture medium to exclude shear-stress effects (Figure 1B). For the positioning of the samples, we used a Delrin structure designed to support 30 cylindrical vials (Figure 1C).

The large-diameter centrifuge system of the ESA was used for hypergravity induction. It is composed of four large rotating arms with a swing gondola at each extremity (Figure 1D), and can support hypergravity levels between $1 \mathrm{~g}$ and $20 \mathrm{~g}$. We performed analyses on proliferating and differentiating rat MSCs provided with and without $20 \mu \mathrm{g} / \mathrm{mL}$ of BTNPs immediately before the altered gravity treatment, as previously described. The sample support was put in an incubator inside a gondola and accelerated at $20 \mathrm{~g}$ for 3 hours at $32^{\circ} \mathrm{C}$.

At the end of the hypergravity stimulation, the proliferating samples were immediately processed for subsequent analysis, while differentiating samples were incubated for further 48 hours in differentiating conditions (in incubator, $37^{\circ} \mathrm{C}, 5 \% \mathrm{CO}_{2}$ ) before the assessment of osteogenesis. Analogous experiments, as normal-gravity controls, were performed, maintaining cells at the same conditions of atmosphere and temperature for 3 hours at $1 \mathrm{~g}$. All the procedures were performed in duplicate.

In summary, we examined the following experimental classes: 1$)$ proliferating cells at $1 \mathrm{~g}$ without BTNPs, 2) proliferating cells at $1 g$ with BTNPs, 3) proliferating cells at $20 g$ without BTNPs, 4) proliferating cells at $20 \mathrm{~g}$ with BTNPs, 5) differentiating cells at $1 g$ without BTNPs, 6) differentiating cells at $1 g$ with BTNPs, 7) differentiating cells at $20 \mathrm{~g}$ without BTNPs, and 8) differentiating cells at $20 \mathrm{~g}$ with BTNPs.

\section{Cytoskeleton/focal adhesion staining and cell shape-descriptor analysis}

Immediately after the treatment, some proliferative samples were processed in order to evaluate the effects of hypergravity and BTNPs on MSC adhesion and shape. To assess changes in morphology, cytoskeleton conformation, and adhesion, 
immunofluorescence with the Cytoskeleton/Focal Adhesion Staining Kit (Millipore) was performed. Cells were incubated for 45 minutes with a vinculin primary monoclonal antibody (mouse antirat, diluted 1:100 in 10\% goat serum in phosphate-buffered saline [PBS]) after fixation with 4\% paraformaldehyde in PBS for 20 minutes at $4^{\circ} \mathrm{C}$, permeabilization for 15 minutes with $0.1 \%$ Triton X-100 (SigmaAldrich), and treatment with a blocking solution (10\% goat serum in PBS) for 1 hour. Thereafter, a staining solution composed of a green fluorescent labeled secondary antibody (goat antimouse, diluted 1:50 in 10\% goat serum), $100 \mu \mathrm{M}$ tetramethylrhodamine isothiocyanate-phalloidin for F-actin labeling, and $1 \mu \mathrm{M}$ 4',6-diamidino-2-phenylindole (DAPI) for nucleus counterstaining were added. Samples were finally washed several times with PBS before observation under a confocal laser-scanning microscope (C2s; Nikon).

Cell shape was analyzed on proliferative samples stained with Coomassie Brilliant Blue ( $0.2 \%$ for 5 minutes $)$. Cell area and different shape descriptors were calculated with ImageJ software (http://rsb.info.nih.gov/ii) analyzing at least 50 welldistinct cells, acquired with an inverted optical microscope (Nikon Eclipse Ti). In particular, the solidity $(S)$, circularity $(C)$, and roundness $(R)$ of cells were investigated according to the following equations: ${ }^{24}$

$$
\text { Roundness }=R=\frac{a}{b}
$$

where $a$ and $b$ are the width and length of the minimum bounding (the smallest rectangle enclosing the selection), respectively,

$$
\text { Circularity }=C=\frac{4 \pi A}{P^{2}}
$$

where $P$ is the perimeter and $A$ is the cell area, and

$$
\text { Solidity }=S=\frac{A}{\text { Convex } A}
$$

where Convex $A$ is the area enclosed by the smallest shell that borders all the points of the cell.

\section{Nanoparticle-internalization analysis}

NP internalization has been investigated by a multimodal microscope with an in-plane resolution of approximately $300 \mathrm{~nm}$ and a resolution of $1 \mu \mathrm{m}$ along the optical axis. Coherent anti-Stokes Raman scattering (CARS) has been exploited to obtain images of cells, based on a degenerate pump-and-probe beam (PaPB) created by a Ti-Sa pulsed laser (Chameleon Vision II; Coherent) and a supercontinuum generator (photonic crystal fiber SCG-800; Newport) that produces a broadband Stokes beam. The beams were chirped through their transmission by two $\mathrm{SF}_{6}$ glass blocks - a $10 \mathrm{~cm}$-long one for the PaPB, and a $15 \mathrm{~cm}$-long one for the Stokes radiation - in order to optimize the spectral resolution. For the excitation of $\mathrm{CH}_{2}$ bonds at a Raman shift of 2,850 $\mathrm{cm}^{-1}$ and thus for the cell imaging, we adjusted the delay between the PaPB and the Stokes beam. For the localization of BTNPs, an $806 \mathrm{~nm}$ PaPB was combined with Stokes photons producing a sum-frequency generation (SFG) signal from BTNPs at approximately $452 \mathrm{~nm}$. The images were subject to analysis with ImageJ software, and the amount of BTNP internalization was calculated as the ratio of the area occupied by the NPs inside the cells and the total cell area, on at least 50 cells for each experimental treatment.

\section{Quantitative real-time reverse- transcription polymerase chain reaction}

Quantitative real-time reverse-transcription polymerase chain reaction (qPCR) was used to investigate the messenger ribonucleic acid (mRNA) transcription of osteogenesis-marker genes (runt related transcription factor 2 [RUNX2], collagen type I alpha-1 [COL1A1], and alkaline phosphatase [ALPL]) and of RHOA (Ras homolog gene family, member A), which regulates osteogenesis-activating $R U N X 2$ following mechanical stimulation..$^{25}$

After the experimental procedures, cells were trypsinized and centrifuged, and the total RNA was extracted from the samples with the High Pure RNA Isolation Kit (Roche) according to the manufacturer's instructions. The quantity and purity of RNA was verified through spectrophotometric analysis (NanoDrop; Thermo Scientific). Thereafter, complementary deoxyribonucleic acid was obtained from the reverse transcription of $100 \mathrm{ng}$ of RNA through iScript ${ }^{\mathrm{TM}}$ Reverse Transcription Supermix (Bio-Rad). The following protocol was used for the retrotranscription: $25^{\circ} \mathrm{C}$ for 5 minutes, $42^{\circ} \mathrm{C}$ for 45 minutes, $48^{\circ} \mathrm{C}$ for 15 minutes, and finally $85^{\circ} \mathrm{C}$ for 5 minutes. The amplification was carried out on the CFX Connect ${ }^{\mathrm{TM}}$ Real-Time PCR Detection System (Bio-Rad) thermocycler with the SsoAdvanced ${ }^{\mathrm{TM}} \mathrm{SYBR}^{\circledR}$ Green Supermix (Bio-Rad). The temperature steps for the amplification reaction were: one cycle at $98^{\circ} \mathrm{C}$ for 30 seconds, 40 cycles at $98^{\circ} \mathrm{C}$ for 3 seconds, and $60^{\circ} \mathrm{C}$ for 7 seconds, a temperature ramp from $65^{\circ} \mathrm{C}$ to $95^{\circ} \mathrm{C}$, with $0.5^{\circ} \mathrm{C} /$ second increments (for melting curve generation). The analysis was carried out in triplicate for each sample. The housekeeping genes adopted were GUSB and RPL19; the cycle threshold $\left(C_{t}\right)$ value relative to the control sample (cultures performed at $1 \mathrm{~g}$, without NP treatment) was considered as the reference for the calculation of 
$\Delta \Delta C_{t}$ (difference between $\Delta C_{t}$ values deriving from difference between $\Delta C_{t}$ of target and housekeeping genes) for the subsequent samples. ${ }^{26}$ Primer sequences (forward and reverse) of the investigated genes are reported in Table 1.

\section{Western blotting}

Western blotting was performed for protein-expression investigation. The analysis was focused on the main proteins involved in the early stage of osteogenesis (ALPL and COL1; glyceraldehyde-3-phosphate dehydrogenase [GAPDH] was adopted as the reference). For protein extraction, after trypsinization and centrifugation, cell pellets were lysed in $50 \mathrm{mM}$ Tris- $\mathrm{HCl}$ (pH 7.6), 2 mM ethylenediaminetetraacetic acid, $100 \mathrm{mM} \mathrm{NaCl}, 1 \%$ Nonidet P40, and antiproteases $1 \times$ (all these reagents from Sigma). Protein quantification was performed through the Pierce ${ }^{\mathrm{TM}}$ BCA Protein Assay Kit (Thermo Scientific) following the manufacturer's protocol. Twenty micrograms of protein for each sample was separated on a $4 \%-15 \%$ Mini-Protean ${ }^{\circledR}$ TGX Stain-Free ${ }^{\text {TM }}$ Gel (Bio-Rad) under reducing conditions, and then transferred to nitrocellulose membrane. The membranes were saturated for 45 minutes with 4\% nonfat dry milk in PBS for blocking nonspecific binding sites, and then probed with primary antibodies against ALPL (rabbit antirat, diluted 1:8,000, Abcam Biotechnology), COL1 (rabbit antirat, diluted 1:1,000, Abcam Biotechnology), or GAPDH (mouse antirat, diluted 1:2,000, Abcam Biotechnology) overnight at $4^{\circ} \mathrm{C}$. Finally, specific secondary horseradish peroxidase-conjugated antirabbit or antimouse antibodies (KPL, final concentration $0.2 \mu \mathrm{g} / \mathrm{mL}$ ) were used, and the immunocomplexes were detected by chemiluminescence (ECL Clarity; Bio-Rad) using the Chemi-Doc ${ }^{\mathrm{TM}}$ XRS+ System (Bio-Rad). The intensity of the bands was quantified through the ChemiDoc XRS+ software by adopting the $1 \mathrm{~g}$ sample values as reference for the relative expression and by normalizing to the GAPDH values.

\section{Alizarin red staining}

Alizarin red solution (Millipore) was used to stain in orange red the calcium deposits of the MSC cultures induced to differentiate. Following paraformaldehyde fixation, cells were incubated with $500 \mu \mathrm{L}$ of alizarin red solution at room temperature for 30 minutes. After extensive washing steps with deionized water, cells were visualized in bright field under the optical microscope for image acquisition. ImageJ was used to detect and automatically quantify the size of alizarin red-positive areas for each experimental group, analyzing at least ten random fields per sample.

\section{Statistical analysis}

All the described experiments were carried out at least in triplicate, and all procedures were replicated twice. With regard to image analysis, data were tested with the nonparametric Kruskal-Wallis analysis followed by the Nemenyi-DamicoWolfe-Dunn post hoc test to assess significance using $\mathrm{R}$ software (http://www.r-project.org). Data are presented as box plots. In particular, each box plot is composed of whiskers indicating the minimum and maximum of the data, while the top and the bottom of the box are the first and third quartiles, respectively; the band inside the box is the median. qPCR data were analyzed with Bio-Rad CFX Manager software. In all cases, data were considered significant at $P<0.05$.

\section{Results \\ Cell morphology and nanoparticle internalization}

Immunofluorescent staining of cytoskeleton (F-actin in red, vinculin in green) of proliferating MSCs qualitatively showed

Table I Primer sequences of target and housekeeping genes

\begin{tabular}{|c|c|c|}
\hline Gene & Symbol & Sequence $\left(5^{\prime}-3^{\prime}\right)$ \\
\hline \multirow[t]{2}{*}{ Runt-related transcription factor 2} & RUNX2 & F- CCCTGAACTCAGCACCAA \\
\hline & & R - AGGATTGTGTCTGCCTGG \\
\hline \multirow[t]{2}{*}{ Collagen, type I, alpha-I } & COLIAI & F - GCAAAGAAGACTTGGACTGT \\
\hline & & R - TTCTGCGTCTGGTGATACA \\
\hline \multirow[t]{2}{*}{ Alkaline phosphatase, liver/bone/kidney } & ALPL & F - GCACAACATCAAGGACATCG \\
\hline & & R - CATCCAGTTCATATTCCACATCAG \\
\hline \multirow[t]{2}{*}{ Ras homolog family member $\mathrm{A}$} & RHOA & F - CTGGTGATTGTTGGTGATGG \\
\hline & & R - AACTCTACCTGCTTCCCGT \\
\hline \multirow[t]{2}{*}{ Glucuronidase, beta } & GUSB & F - TCACCATCGCCATCAACAACAC \\
\hline & & R - GCTTATGTCCTGGACGAAGTAACC \\
\hline \multirow[t]{2}{*}{ Ribosomal protein LI9 } & RPLI9 & F - AAGATTGACCGTCATATGTATCAC \\
\hline & & R - CCTTGTCTGCCTTCAGTTTG \\
\hline
\end{tabular}


evident effects following hypergravity treatment (Figure 2). In particular, $20 \mathrm{~g}$-treated cells appeared more stretched and with F-actin organized in parallel fibers with respect to the $1 \mathrm{~g}$ control cultures.

In order to gain quantitative data about the influence of hypergravity and NPs on cell morphology, we calculated cell area and cell-shape descriptors (solidity, circularity, roundness) on Coomassie blue-stained cultures in proliferative conditions immediately after the hypergravity treatment (Figure 3A). Concerning area evaluation (Figure 3B), we observed a significant increase when cells were treated with BTNPs $\left(8,648 \pm 2,419 \mu \mathrm{m}^{2}\right)$, hypergravity $\left(9,735 \pm 2,795 \mu \mathrm{m}^{2}\right)$,

$1 \mathrm{~g}$

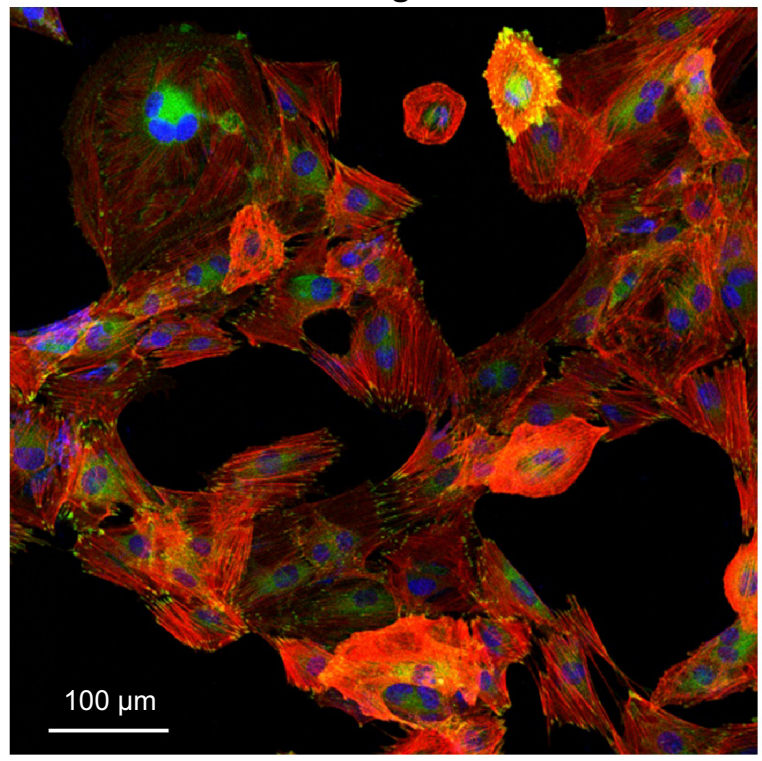

$20 \mathrm{~g}$

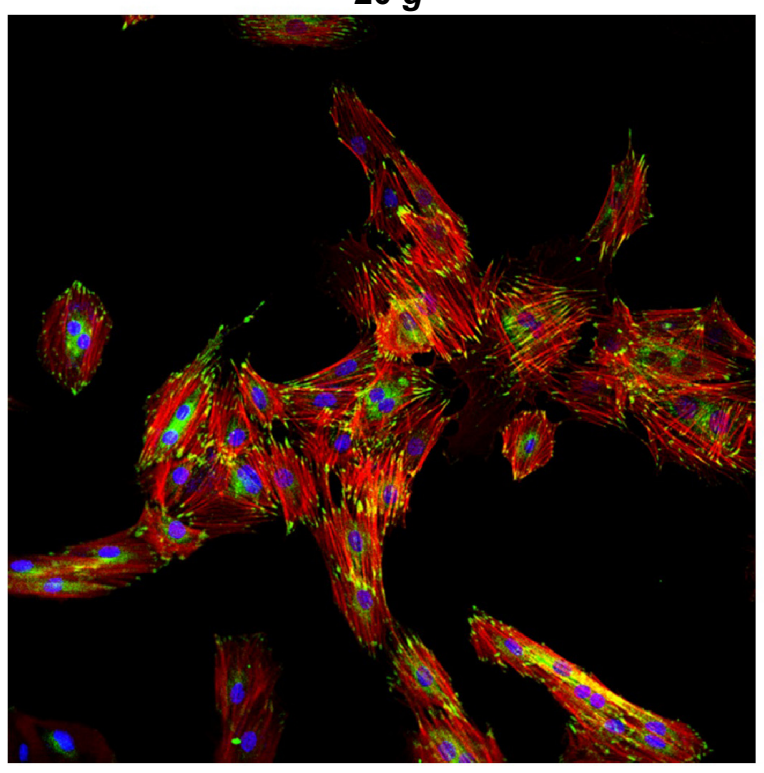

or with the combination of the two stimuli $(9,733 \pm 2,739$ $\left.\mu \mathrm{m}^{2}\right)$, compared to the control at $1 \mathrm{~g}$ not treated with the NPs $\left(6,155 \pm 1,602 \mu \mathrm{m}^{2}\right)(P<0.05$ in all the three treatments with respect to the control). The solidity of the cells (Figure $3 \mathrm{C}$ ) after hypergravity stimulation, independently of the presence of BTNPs $(0.83 \pm 0.05$ and $0.81 \pm 0.04$ for $20 \mathrm{~g}$ and $20 \mathrm{~g}+$ BTNPs, respectively) was significantly lower than that of the cells grown at $1 g(0.93 \pm 0.02$ and $0.98 \pm 0.02$ for $1 g$ and $1 g+$ BTNPs, respectively; $P<0.05$ in the $20 \mathrm{~g}$ treatments with respect to the $1 \mathrm{~g}$ treatments). A similar trend was observed for circularity (Figure 3D), the distributions of which denoted a significant decrease of the values of proliferating MSCs subjected to $20 \mathrm{~g}$

\section{$1 g+$ BTNPs}

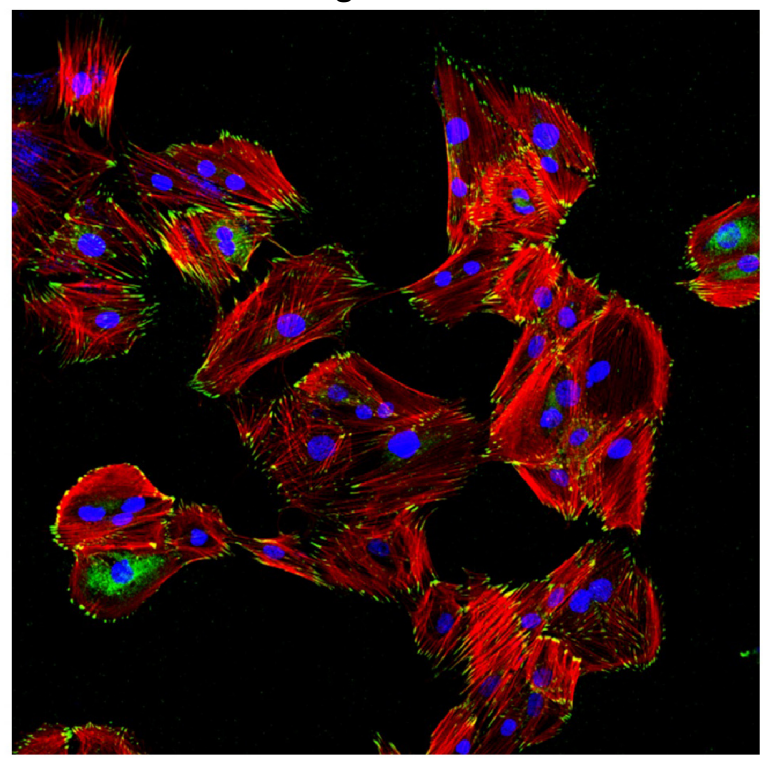

$20 g+$ BTNPs

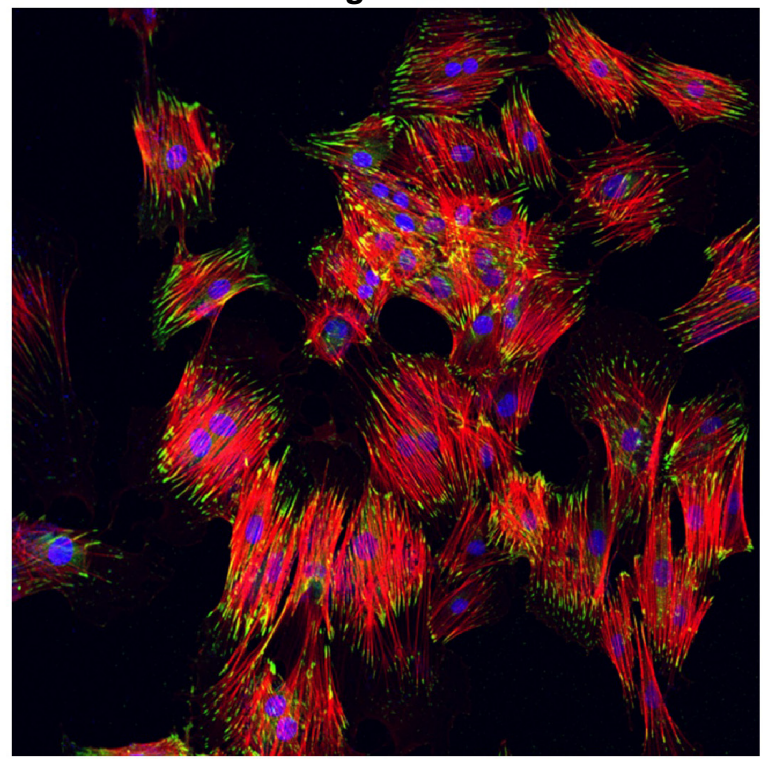

Figure 2 Immunofluorescence staining. Vinculin (green) and F-actin (red) in proliferating mesenchymal stem cells after the 3-hour treatment. Nuclei counterstained in blue. Abbreviation: BTNPs, barium titanate nanoparticles. 
A

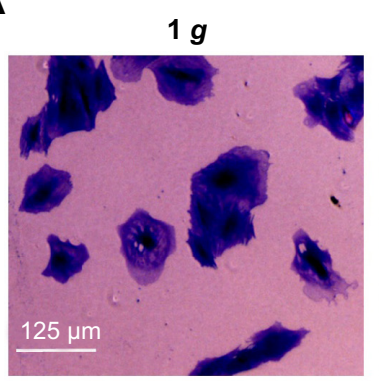

B

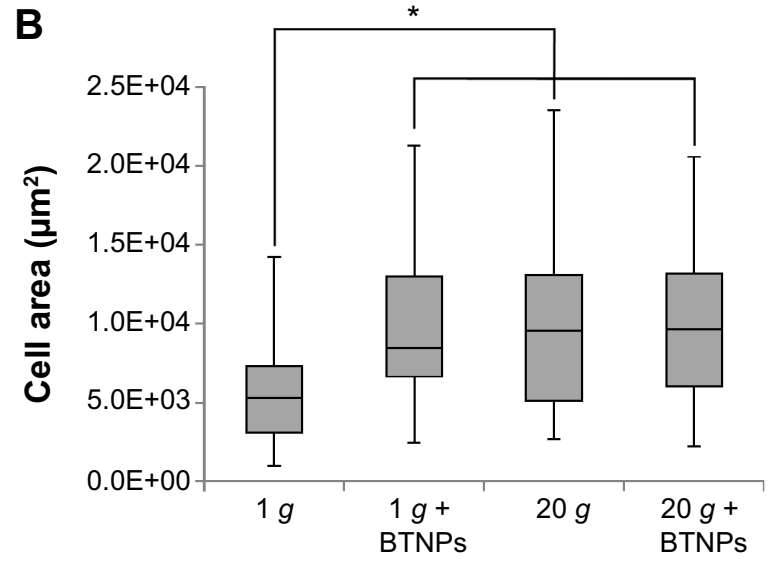

D

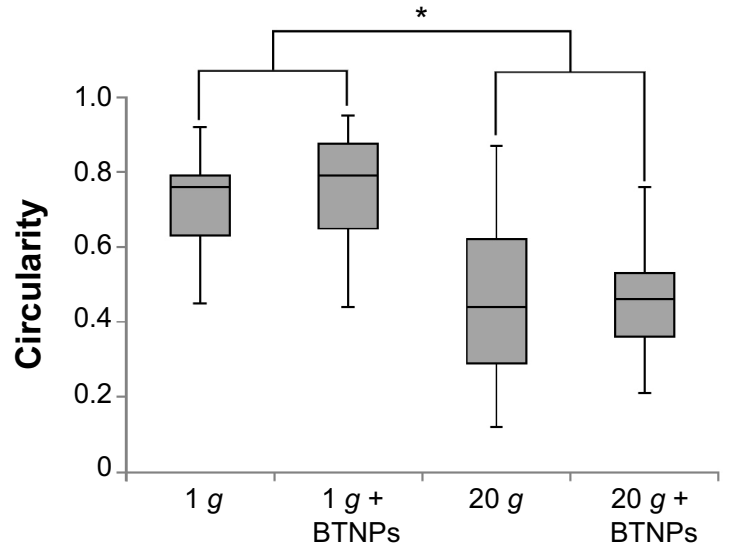

$1 g+$ BTNPs

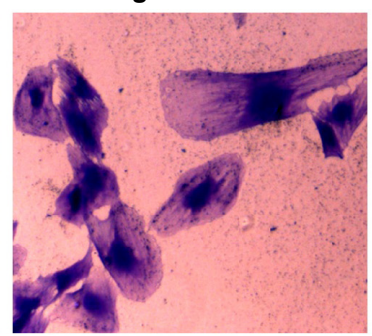

*
BTNPs
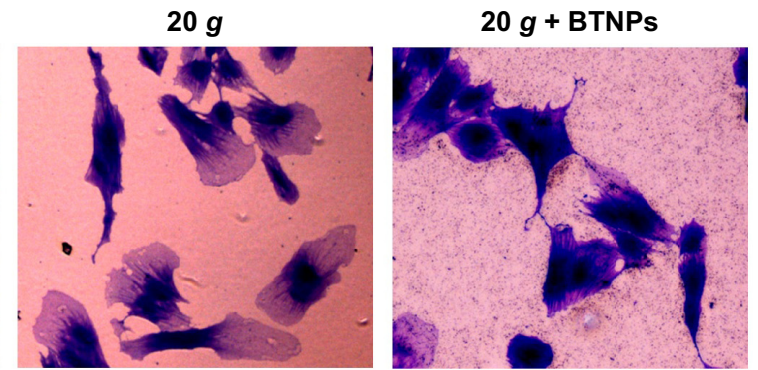

C

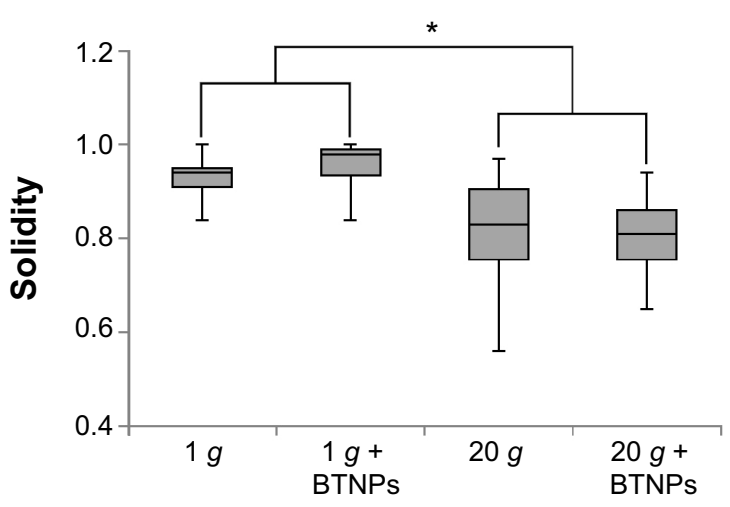

E

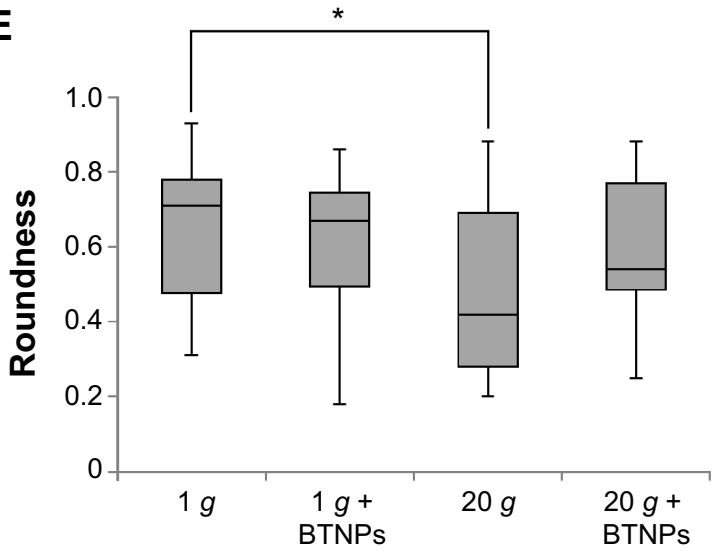

Figure 3 Cell morphology. Morphometric analysis of mesenchymal stem cells in proliferation immediately after the treatment.

Notes: $* P<0.05$. Coomassie Brilliant Blue staining (A); area distributions (B); solidity distributions (C); circularity distributions (D); roundness distributions (E).

acceleration $(0.44 \pm 0.10$ and $0.46 \pm 0.06$ for $20 g$ and $20 g+$ BTNPs, respectively) with respect to $1 g$ conditions $(0.72 \pm 0.07$ and $0.77 \pm 0.08$ for $1 g$ and $1 g+$ BTNPs, respectively) $(P<0.05)$. Finally, we found an analogous trend in the reduction of the roundness (Figure $3 \mathrm{E}$ ) for the cells that underwent hypergravity treatment $(0.42 \pm 0.13$ and $0.54 \pm 0.10$ for $20 g$ and $20 g+$ BTNPs, respectively) when compared to the controls at $1 g(0.71 \pm 0.11$ and $0.67 \pm 0.08$ for $1 g$ and $1 g+$ BTNPs, respectively). Nevertheless, only the roundness reduction at $20 \mathrm{~g}$ was statistically significant with respect to $1 g(P<0.05)$.

Results of nonlinear microscopy on proliferating and differentiating cells internalizing BTNPs at $1 g$ and $20 g$ are reported in Figure 4. Figure 4A depicts images representative of the four experimental conditions, highlighting a perinuclear cytoplasmic accumulation of BTNPs. The CARS signal from cells is represented in green, the SFG signal from NPs in red: we can appreciate the emission spectrum from a bundle of NPs when irradiated with the PaPB and the Stokes beam in Figure 4B. Four individual bands are visible, originating from: a second harmonic generation SHG signal from the $806 \mathrm{~nm}$ pump beam, SFG from the combination of the $806 \mathrm{~nm}$ pump beam and the portion of the Stokes beam temporarily overlapping to it (ie, corresponding to approximately $1,045 \mathrm{~nm}$ ), broadband second harmonic generation 
A
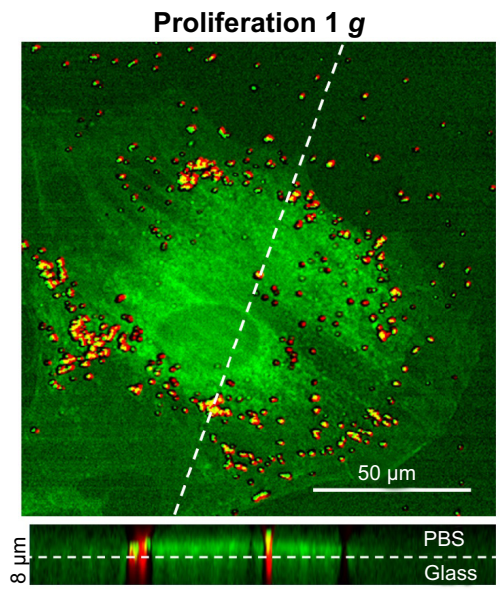

Proliferation $20 \mathrm{~g}$
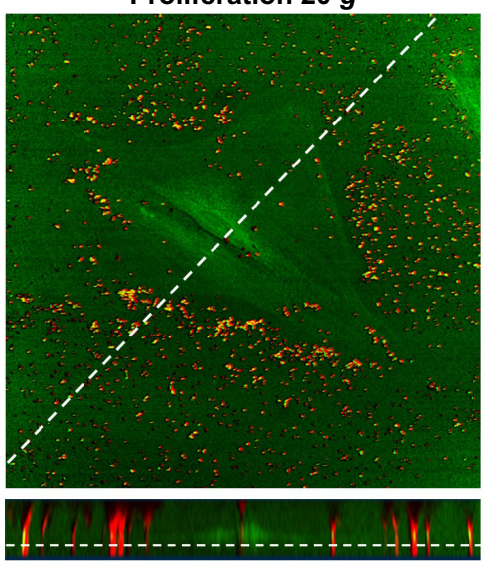

B

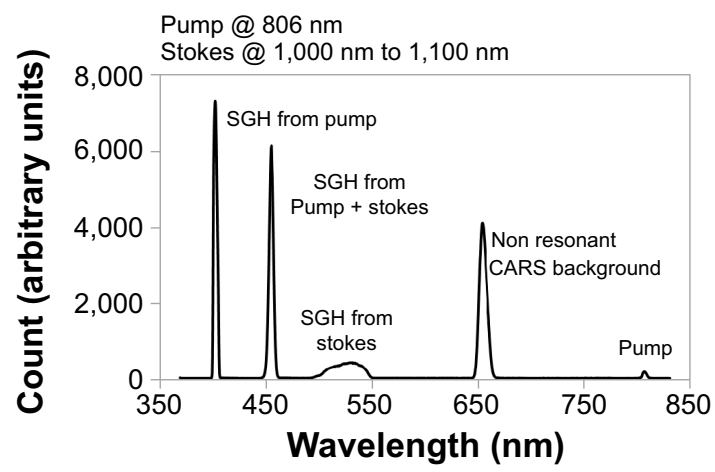

Differentiation $1 \mathrm{~g}$

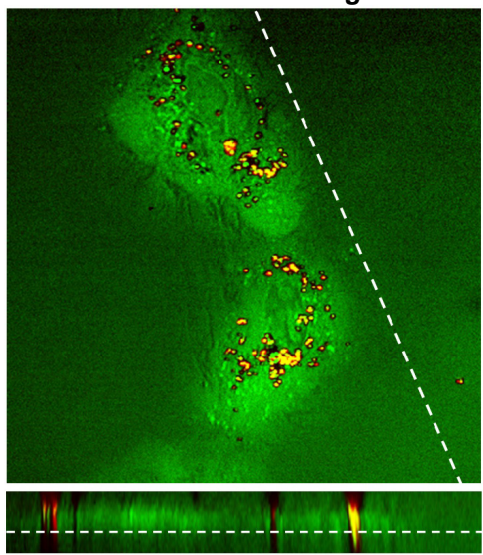

Differentiation $20 \mathrm{~g}$

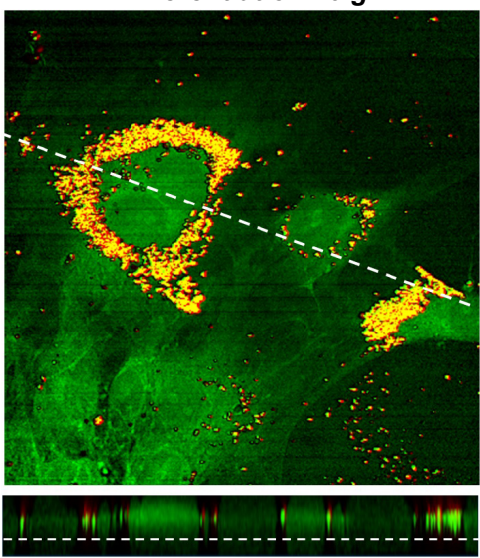

C

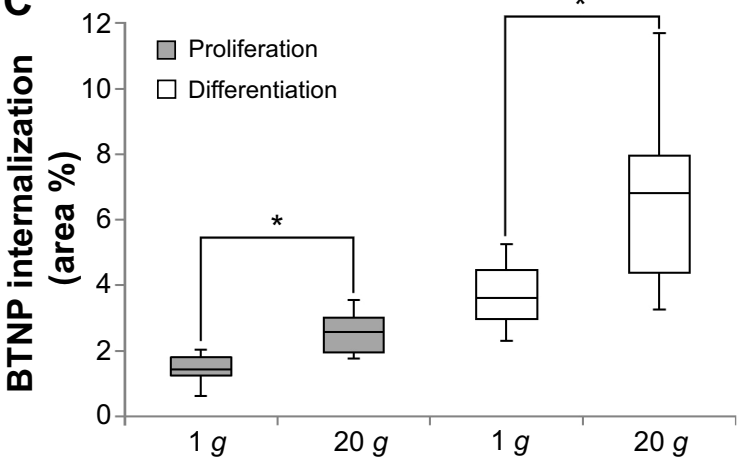

Figure 4 Barium titanate nanoparticle (BTNP)-internalization assessment.

Notes: $* P<0.05$. Single Z-slice, along a side projection, showing BTNPs (in red, owing to the sum-frequency generation [SFG] signal) inside the cells (in green, owing to the coherent anti-Stokes Raman scattering [CARS] signal from the $\mathrm{CH}_{2}$ bonds) (A). Four bands are visible from the emission spectrum from a bundle of nanotubes when illuminated with the pump-and-probe and Stokes beams: second harmonic generation (SHG) from the $806 \mathrm{~nm}$ beam, SFG from the combination of the $806 \mathrm{~nm}$ beam and the portion of the Stokes beam temporarily overlapping it (ie, corresponding to $\sim 1,045 \mathrm{~nm}$ ), broadband SHG from the Stokes beam, and nonresonant CARS signal (B). Quantification of BTNP internalization (C).

from the Stokes beam, and nonresonant CARS background. A fifth band indicates the pump beam partially repressed by a filter. A quantitative evaluation of NP uptake (Figure 4C) performed in terms of percentage of the cytoplasmic area occupied by the BTNPs revealed a strong enhancement of BTNP internalization in cells that underwent hypergravity stimulation $(P<0.05)$, both in differentiation $(6.8 \pm 0.8 \%$ at $20 \mathrm{~g}, 3.6 \pm 0.3 \%$ at $1 \mathrm{~g})$ and in proliferation $(2.7 \pm 0.3 \%$ at $20 \mathrm{~g}$, $1.4 \pm 0.1 \%$ at $1 \mathrm{~g}$ ) conditions. The generally higher internalization in differentiation conditions was simply due to a longer BTNP incubation time $(3+48$ hours for differentiation samples versus 3 hours for proliferation samples). 


\section{Cell-differentiation assessment: gene and protein analysis and alizarin red staining}

The evaluation of the gene transcription through qPCR of samples under differentiation conditions is shown in the plots of Figure 5A. RUNX2 was significantly upregulated in $20 \mathrm{~g}$-treated samples (1.5-fold at $20 \mathrm{~g}, 1.8$-fold at $20 \mathrm{~g}+$ BTNPs) with respect to the $1 g$ and $1 g$ + BTNP cultures. COL1A1 transcription was significantly enhanced (1.5-fold) only in the double-stimulation $20 \mathrm{~g}+\mathrm{BTNPs}$, while downregulation ( 0.6 -fold) was noticed in cultures performed at $1 \mathrm{~g}$ in the presence of the NPs. Finally, once again $A L P L$ was significantly upregulated (1.6-fold) when cells were synergistically stimulated with hypergravity and NPs with respect to all the other treatments.

To evaluate how hypergravity affected the osteogenic pathway, we focused also on the transcription of $R H O A$ in proliferating cells (thus without any osteoinductive chemical cue) immediately after the hypergravity treatment, since $R H O A$ codes for a small guanosine triphosphatase protein known to play a key role in osteogenesis following mechanical stimulation. ${ }^{27}$ Figure 5B shows a significant upregulation $(P<0.05)$ of $R H O A$ mRNA transcription in all treatments ( $1 g+$ BTNPs 2.0-fold, $20 g$ 2.5-fold, $20 g$ + BTNPs 2.8-fold) with respect to the $1 g$ control not treated with BTNPs. Moreover, this is interesting to highlight, as the $20 \mathrm{~g}+\mathrm{BTNP}$ group revealed a significant upregulation of $R H O A$ with respect to the $1 g+$ BTNP group (1.4-fold, $P<0.05$ ), thus suggesting a role of both NPs and hypergravity in the enhancement of MSC differentiation.

In order to assess the effects of our stimulation procedures at the protein-expression level also, Western blotting of collagen type I and alkaline phosphatase was performed, and the results are reported in Figure 6A. Quantitative values obtained evaluating band intensities (Figure 6B) proved an enhancement of collagen type I expression in all the experimental groups with respect to the control at $1 \mathrm{~g}$ not treated with BTNPs, but only hypergravity conditions were statistically significant (20 $g$ 1.3-fold, $20 g$ + BTNPs 1.5 -fold; $P<0.05$ ). Moreover, the increasing expression of collagen type I in the synergic stimulation hypergravity + NPs is significant $(P<0.05)$ when compared to the $1 g+$ BTNP treatment (1.3-fold, Figure 6B). With regard to alkaline phosphatase, no significant expression differences were detected among any of the treatments.

The alizarin red assay (Figure 7A) revealed an increase of the calcium deposition (in terms of size of calcium nodules) in samples treated with BTNPs both at $20 \mathrm{~g}$ $\left(11,909 \pm 1,691 \mu \mathrm{m}^{2}, 45 \%\right.$ higher with respect to $20 \mathrm{~g}$ without BTNPs $\left.-8,192 \pm 1,988 \mu \mathrm{m}^{2}\right)$ and at $1 \mathrm{~g}\left(8,813 \pm 2,615 \mu \mathrm{m}^{2}, 74 \%\right.$ higher with respect to $1 g$ without BTNPs $-5,071 \pm 2,265 \mu \mathrm{m}^{2}$ ). Interestingly, there was also around a $35 \%$ increment in $20 \mathrm{~g}+$ BTNP cultures with respect to the $1 g+$ BTNP ones; however, statistically significant differences were only detected in the samples stimulated at $20 \mathrm{~g}+$ BTNPs with respect both to $1 \mathrm{~g}$ $(134 \%, P<0.005)$ and $20 g(45 \%, P<0.005$; Figure $7 \mathrm{~B})$.

\section{Discussion}

It is widely recognized that several kinds of cells, including endothelial cells, ${ }^{28}$ osteoblasts, ${ }^{29}$ myoblasts, ${ }^{30}$ and stem cells, ${ }^{31}$ are sensitive to a change of gravity-force intensity. In particular, it was found that hypergravity treatments could

\section{A}

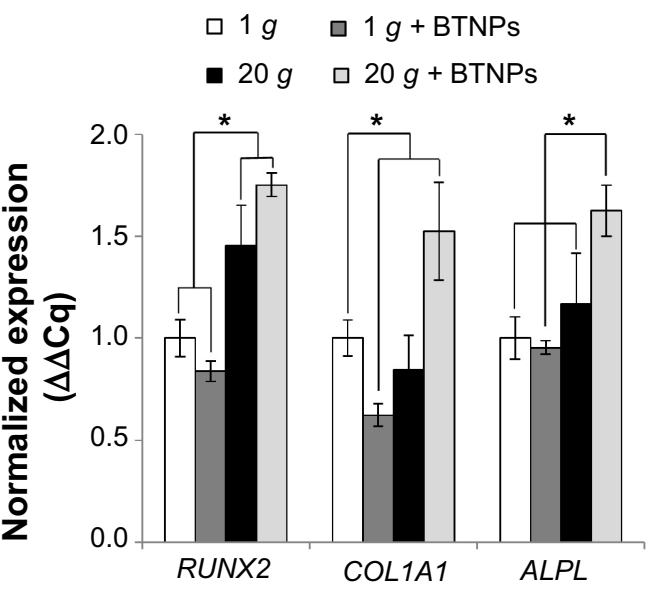

B

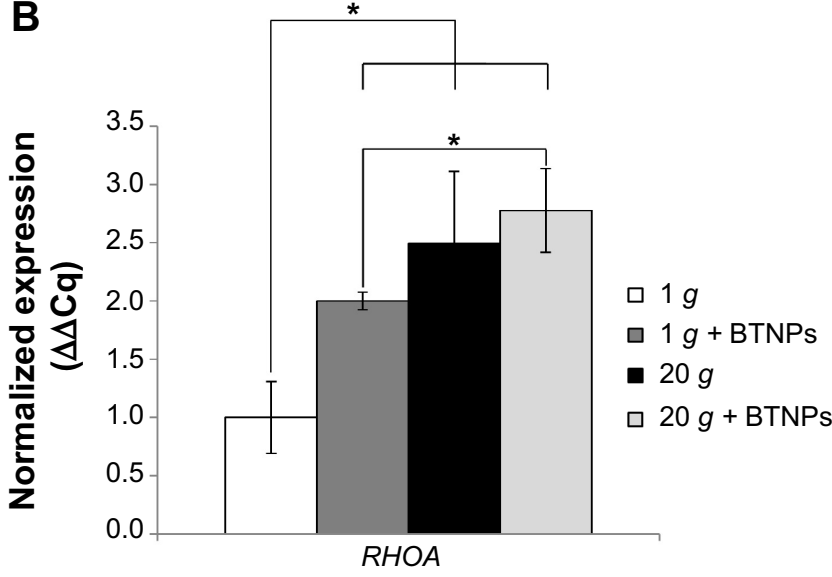

Figure 5 Quantification of transcribed genes.

Notes: $* P<0.05$. Analysis of osteogenesis-marker genes in differentiating cells 48 hours after treatment: runt-related transcription factor 2 (RUNX2), type I collagen alpha- I (COLIAI), and alkaline phosphatase (ALPL) (A). mRNA quantification of Ras homolog family member $\mathbf{A}(R H O A)$ in proliferating cells immediately after stimulation (B). Abbreviation: BTNPs, barium titanate nanoparticles. 

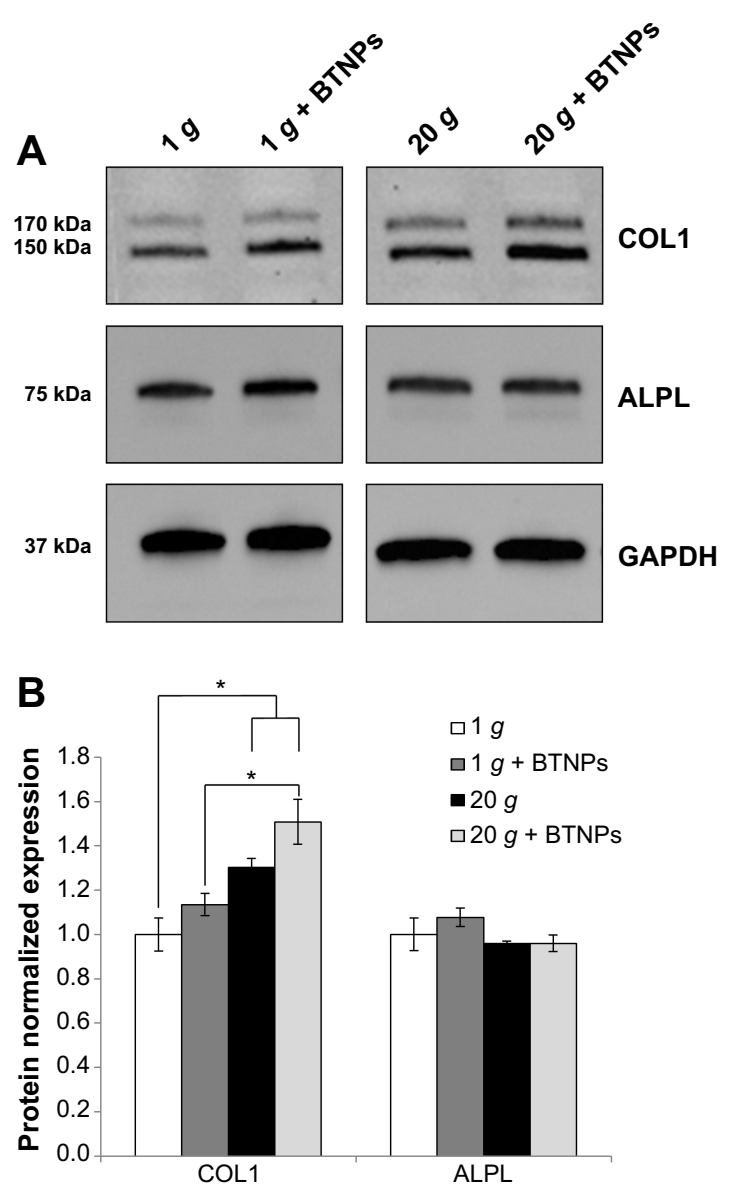

Figure 6 Protein-expression analysis.

Notes: Western blotting 48 hours after treatment for collagen type I (COLI; the largest band [ $150 \mathrm{kDa}]$ corresponds to the two $\alpha \mathrm{l}$ chains, the smallest one indicates the $\alpha 2$ chain [170 kDa]) and for alkaline phosphatase (ALPL; $75 \mathrm{kDa}$ ). Glyceraldehyde-3-phosphate dehydrogenase (GAPDH) was used as the reference. Representative results $(\mathbf{A})$ and quantitative evaluation of the relative intensities of the Western blotting bands (B).

Abbreviation: BTNPs, barium titanate nanoparticles.

enhance osteogenesis in osteoblast-like cells. ${ }^{32}$ In this paper, we have reported on the hypothesis that upon hypergravity stimulation and BTNP administration, MSCs enhance their commitment toward osteogenesis.

Mechanical forces are well known to induce cytoskeleton rearrangements, and these conformation changes deeply affect stem cell behavior. ${ }^{33}$ To analyze these phenomena in our experimental conditions, we performed a quantitative evaluation of several cell-shape descriptors. The morphometric analysis demonstrated that following a hypergravity treatment, cells were less circular, more spread, and cover a larger area when compared to the $1 g$ control. Overall, the characterization of cell shape and morphology showed that an increment of gravitational force, both in the presence or not of BTNPs, provided as a consequence a more irregular and spread morphology. This effect, consistent with other
A

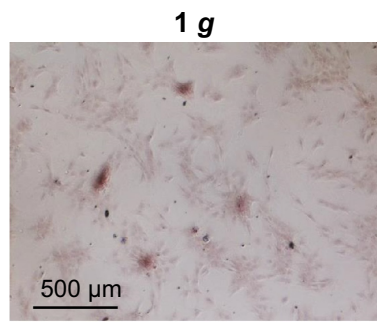

$20 \mathrm{~g}$
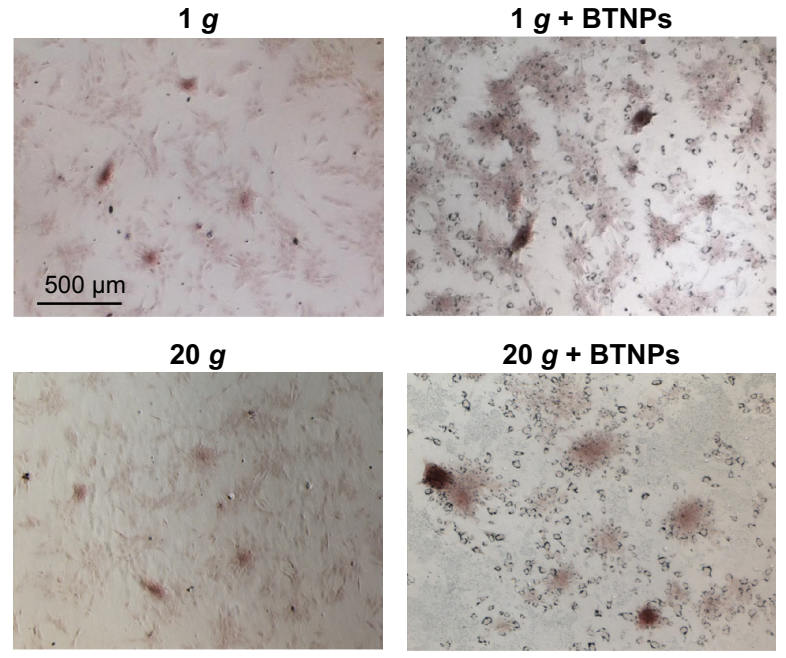

$20 \mathrm{~g}+\mathrm{BTNPs}$

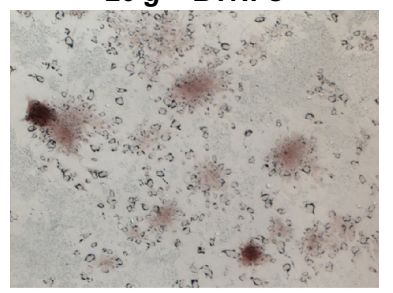

B

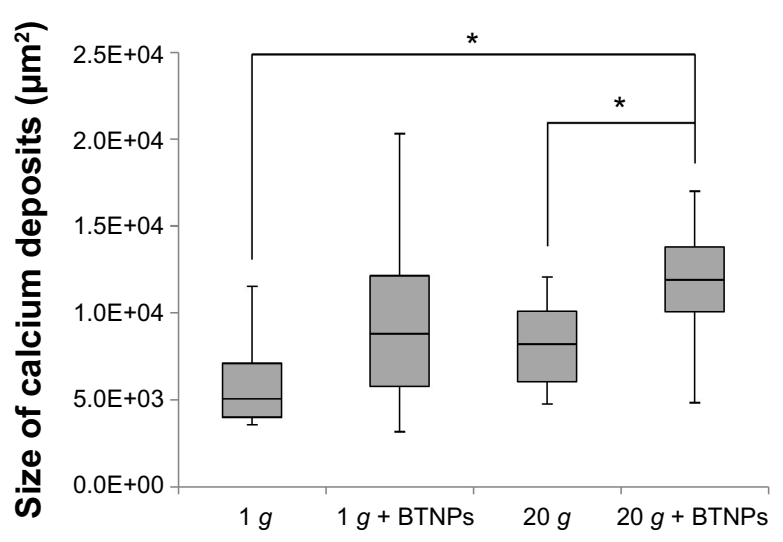

Figure 7 Mineralization evaluation.

Notes: $* P<0.005$. Alizarin red assay $(\mathbf{A})$ and size of calcium deposits $(\mathbf{B})$ at 48 hours of differentiation posttreatment.

Abbreviation: BTNPs, barium titanate nanoparticles.

results available in the literature, ${ }^{34}$ could contribute to the maturation toward osteoblasts, given that spread cells are committed to osteogenesis, and conversely, a rounded shape promotes adipogenesis. ${ }^{35}$

Furthermore, the F-actin organization in parallel and welldefined stress fibers qualitatively observed after hypergravity stimulation is a further hint of cytoskeleton-tension enhancement, and consequently of the mechanotransduction leading to osteogenesis (mediated by RHOA and RUNX2). ${ }^{36}$

Among the impressive variety of inorganic nanomaterials investigated in nanomedicine, BTNPs are still relatively unexplored yet most promising, owing to their good biocompatibility, ${ }^{21}$ osteoinductive properties,${ }^{19}$ and nonlinear optical properties. ${ }^{22}$ Nonlinear microscopy performed thanks to these particular features allowed the enhancement of NP uptake following hypergravity treatment to be assessed. Our results proved that hypergravity enhances NP internalization, both in proliferation and differentiation cultures. This result is 
particularly interesting for in vitro drug-delivery applications. A number of studies in the literature have aimed to enhance nanocarrier internalization by using physical approaches, such as ultrasounds ${ }^{37}$ or magnetic fields. ${ }^{38}$ However, these methods suffer some disadvantages related to cell damage and/or undesired effects on metabolism and functions. Hypergravity could therefore represent a valid alternative for enhanced drug and gene delivery mediated by NPs for plenty of in vitro applications.

Since osteogenic differentiation was induced for just 2 days (because of technical constrains at the ESA facilities), the mRNA-expression analysis was focused on genes involved in the early stage of osteogenesis (ie, RUNX2, COL1A1, $A L P L)$. The obtained results, which indicated general gene upregulation following hypergravity and BTNP treatments, are particularly interesting, since $R U N X 2$ encodes for the key transcription factor that induces osteogenic differentiation, ${ }^{39}$ COL1A1 product is the major component of the bone organic matrix, ${ }^{40}$ and $A L P L$ is involved in the mineralization process. ${ }^{41}$ Corroborating our findings, similar results were obtained following MSC stimulation at $2 g$ and at $10 g^{42,43}$

Our results highlight that the performed stimulations (hypergravity and incubation with BTNPs) can synergistically act in improving the early stage maturation of MSCs toward osteoblasts. Western blotting showed an increment of COL1 expression in hypergravity-stimulated cultures, these being data in line with other findings on osteoblastlike cells treated for 24 hours at $13 \mathrm{~g}$, which demonstrated a significant increment in collagen expression. ${ }^{44}$ In our case, moreover, the combination of hypergravity with BTNP incubation further increased collagen production. Therefore, increased COL1 mRNA expression was also translated to enhanced protein production; instead, concerning ALPL, we observed upregulation of the mRNA, but not enhancement of the protein expression, most probably because of a too-early stage of differentiation. ${ }^{45}$ Obviously, gene activation does not always result in an increase in protein levels, because of the translation-regulation and protein-degradation mechanisms; however, even though this point is interesting, it is out of the scope of this work to deeply analyze the molecular mechanisms of transduction regulation involved in this process.

Finally, we investigated the osteoblast phenotype through the alizarin red assay, which revealed an enhancement of calcium deposits in the presence of BTNPs and hypergravity treatment with respect to the other experimental groups. Indeed, the size of calcium nodules in samples under hypergravity conditions and BTNP treatment was found to be significantly higher when compared to the hypergravity stimulation alone, thus further suggesting a synergic effect of the double stimulation. These data are consistent with the results obtained by Prodanov et al who demonstrated an increase of calcium content in MSCs cultured on nanotextured substrate and subjected to a $10 \mathrm{~g}$ treatment. ${ }^{43}$

Taken together, all the obtained results suggest two hypotheses about the mechanism of MSC osteogenesis enhancement following hypergravity treatment and BTNP incubation. The first hypothesis is based on the already proven osteoinduction effectiveness of BTNPs: ${ }^{46}$ as NP uptake is increased following hypergravity treatment, osteogenic maturation is enhanced because of a higher number of internalized BTNPs. However, we have to consider also improvements of MSC maturation when hypergravity is applied without the presence of NPs.

In order to understand whether hypergravity could itself act as a mechanical cue able to induce osteogenesis, we performed an analysis of the transcription of RHOA, as the activity of this gene is altered following cell-shape changes, and more in general following mechanical stimulation of cells. ${ }^{47}$ Our results provide the evidence that a 3-hour $20 \mathrm{~g}$ stimulation makes cells more spread and elongated, reducing their circularity. Several studies have reported that cell shape affects $R H O A$ regulation: ${ }^{48-50}$ spread cells cause $R H O A$ activation that responds to mechanical stimuli enhancing cell tension and stiffness, and upregulating biochemical factors for the induction of the osteogenic pathway, while adipogenesis is inhibited. We therefore analyzed $R H O A$ transcription in the absence of any osteoinductive chemical stimulation and immediately after the treatments. A significant increase of RHOA mRNA was observed in both $1 \mathrm{~g}+\mathrm{BTNP}$ and in $20 \mathrm{~g}$ treatments, thus demonstrating that both stimuli are involved in the activation of RUNX2 transcription (triggered by RHOA product), and thus that both stimuli are osteoinductive. In a recent work, ${ }^{19}$ it was indeed demonstrated that BTNPs are able to mechanically stimulate MSCs by remodeling their cytoskeleton and by increasing their stiffness. Therefore, the RHOA upregulation we observed after BTNP treatment at $1 \mathrm{~g}$ is consistent with the reported mechanical stimulation induced by the NPs. Interestingly, the combination of BTNPs and hypergravity had an even more pronounced effect on the upregulation of $R H O A$ with respect to the single treatments, thus indicating that their combination intensifies osteogenesis. We can thus deduce that hypergravity acts as an osteoinductuive stimulus per se, and at the same time, by enhancing NP internalization, further increases the osteoinductive potential of the BTNPs, thus achieving a double-level and synergic effect following the applied treatments. 


\section{Conclusion}

The goal of this research was to propose new strategies to overcome difficulties in the osteogenic differentiation of MSCs. Collected data demonstrated a short treatment (3 hours) at $20 \mathrm{~g}$ combined with incubation with $20 \mu \mathrm{g} / \mathrm{mL}$ of BTNPs synergistically promoted the osteogenesis of MSCs, evaluated both at the gene and phenotype levels. Hypergravity, in addition to providing per se osteogenic stimulation, is able to promote NP uptake, thus further enhancing NP effects at low doses. All the collected results, even if preliminary, are promising for the elaboration of new approaches in several biomedical fields, including drug delivery, tissue engineering, and regenerative medicine.

\section{Acknowledgments}

The experiments reported in this paper were performed within the framework of the "Spin Your Thesis! 2013" program organized by the ESA Education Office. The authors are particularly grateful to the staff of the ESA Education Office, to the Technical Directorate of the ESA, and to the European Low Gravity Research Association for their constant support before, during, and after the campaign.

\section{Disclosure}

The authors report no conflicts of interest in this work.

\section{References}

1. Ogneva IV. Cell mechanosensitivity: mechanical properties and interaction with gravitational field. Biomed Res Int. 2013;2013:598461.

2. Papachroni KK, Karatzas DN, Papavassiliou KA, Basdra EK, Papavassiliou AG. Mechanotransduction in osteoblast regulation and bone disease. Trends Mol Med. 2009;15(5):208-216.

3. Roca-Cusachs P, Sunyer R, TrepatX. Mechanical guidance of cell migration: lessons from chemotaxis. Curr Opin Cell Biol. 2013;25(5):543-549.

4. Chen JC, Jacobs CR. Mechanically induced osteogenic lineage commitment of stem cells. Stem Cell Res Ther. 2013;4(5):107.

5. Slentz DH, Truskey GA, Kraus WE. Effects of chronic exposure to simulated microgravity on skeletal muscle cell proliferation and differentiation. In Vitro Cell Dev Biol Anim. 2001;37(3):148-156.

6. Adrian A, Schoppmann K, Sromicki J, et al. The oxidative burst reaction in mammalian cells depends on gravity. Cell Commun Signal. 2013; 11:98.

7. Wu X, Li SH, Lou LM, Chen ZR. The effect of the microgravity rotating culture system on the chondrogenic differentiation of bone marrow mesenchymal stem cells. Mol Biotechnol. 2013;54(2):331-336.

8. Zhang X, Nan Y, Wang H, et al. Model microgravity enhances endothelium differentiation of mesenchymal stem cells. Naturwissenschaften. 2013;100(2):125-133.

9. Chen J, Liu R, Yang Y, et al. The simulated microgravity enhances the differentiation of mesenchymal stem cells into neurons. Neurosci Lett. 2011;505(2):171-175

10. Ling SK, Wang R, Dai ZQ, et al. Pretreatment of rat bone marrow mesenchymal stem cells with a combination of hypergravity and 5 -azacytidine enhances therapeutic efficacy for myocardial infarction. Biotechnol Prog. 2011;27(2):473-482.
11. Chang D, Xu H, Guo Y, et al. Simulated microgravity alters the metastatic potential of a human lung adenocarcinoma cell line. In Vitro Cell Dev Biol Anim. 2013;49(3):170-177.

12. Tanaka H, Tanaka S, Sekine K, et al. The generation of pancreatic $\beta$-cell spheroids in a simulated microgravity culture system. Biomaterials. 2013;34(23):5785-5791.

13. van Loon JJ, van Laar MC, Korterik JP, et al. An atomic force microscope operating at hypergravity for in situ measurement of cellular mechano-response. J Microsc. 2009;233(2):234-243.

14. Dhanasekaran M, Indumathi S, Lissa RP, Harikrishnan R, Rajkumar JS, Sudarsanam D. A comprehensive study on optimization of proliferation and differentiation potency of bone marrow derived mesenchymal stem cells under prolonged culture condition. Cytotechnology. 2013; 65(2):187-197.

15. Ferreira L, Karp JM, Nobre L, Langer R. New opportunities: the use of nanotechnologies to manipulate and track stem cells. Cell Stem Cell. 2008;3(2):136-146.

16. Lee JT, Jung JW, Choi JY, Kwon TG. Enhanced bone morphogenic protein adenoviral gene delivery to bone marrow stromal cells using magnetic nanoparticle. J Korean Assoc Oral Maxillofac Surg. 2013;39(3):112-119.

17. Yang K, Cao W, Hao X, et al. Metallofullerene nanoparticles promote osteogenic differentiation of bone marrow stromal cells through BMP signaling pathway. Nanoscale. 2013;5(3):1205-1212.

18. Oliveira JM, Sousa RA, Kotobuki N, et al. The osteogenic differentiation of rat bone marrow stromal cells cultured with dexamethasone-loaded carboxymethylchitosan/poly(amidoamine) dendrimer nanoparticles. Biomaterials. 2009;30(5):804-813.

19. Ciofani G, Ricotti L, Canale C, et al. Effects of barium titanate nanoparticles on proliferation and differentiation of rat mesenchymal stem cells. Colloids Surf B Biointerfaces. 2013;102:312-320.

20. Park YJ, Hwang KS, Song JE, Ong JL, Rawls HR. Growth of calcium phosphate on poling treated ferroelectric $\mathrm{BaTiO}_{3}$ ceramics. Biomaterials. 2002;23(18):3859-3864.

21. Ciofani G, Danti S, Moscato S, et al. Preparation of stable dispersion of barium titanate nanoparticles: potential applications in biomedicine. Colloids Surf B Biointerfaces. 2010;76(2):535-343.

22. Staedler D, Magouroux T, Hadji R, et al. Harmonic nanocrystals for biolabeling: a survey of optical properties and biocompatibility. ACS Nano. 2012;6(3):2542-2549.

23. Ciofani G, Danti S, D’Alessandro D, Moscato S, Petrini M, Menciassi A. Barium titanate nanoparticles: highly cytocompatible dispersions in glycol-chitosan and doxorubicin complexes for cancer therapy. Nanoscale Res Lett. 2010;5(7):1093-1101.

24. Siani A, Robert-Nicoud G, Cellesi F, Tirelli N. Quantitative descriptors for the effect of nature/mechanical properties of solid substrates on fibroblast morphology. J Appl Biomater Funct Mater. 2012;10(3): 265-272.

25. Arnsdorf EJ, Tummala P, Kwon RY, Jacobs CR. Mechanically induced osteogenic differentiation - the role of RhoA, ROCKII and cytoskeletal dynamics. J Cell Sci. 2009;122(Pt 4):546-553.

26. Vandesompele J, De Preter K, Pattyn F, et al. Accurate normalization of real-time quantitative RT-PCR data by geometric averaging of multiple internal control genes. Genome Biol. 2002;3(7):34.

27. Buravkova LB, Gershovich PM, Gershovich JG, Grigor'ev AI. Mechanisms of gravitational sensitivity of osteogenic precursor cells. Acta Naturae. 2010;2(1):28-36.

28. Versari S, Villa A, Bradamante S, Maier JA. Alterations of the actin cytoskeleton and increased nitric oxide synthesis are common features in human primary endothelial cell response to changes in gravity. Biochim Biophys Acta. 2007;1773(11):1645-1652.

29. Kacena MA, Todd P, Gerstenfeld LC, Landis WJ. Experiments with osteoblasts cultured under hypergravity conditions. Microgravity Sci Technol. 2004;15(1):28-34.

30. Ciofani G, Ricotti L, Rigosa J, Menciassi A, Mattoli V, Monici M. Hypergravity effects on myoblast proliferation and differentiation. J Biosci Bioeng. 2012;113(2):258-261. 
31. Meng R, Xu HY, Di SM, et al. Human mesenchymal stem cells are sensitive to abnormal gravity and exhibit classic apoptotic features. Acta Biochim Biophys Sin (Shanghai). 2011;43(2):133-142.

32. Furutsu M, Kawashima K, Negishi Y, Endo H. Bidirectional effects of hypergravity on the cell growth and differentiated functions of osteoblastlike ROS17/2.8 cells. Biol Pharm Bull. 2000;23(10):1258-1261.

33. Kelly DJ, Jacobs CR. The role of mechanical signals in regulating chondrogenesis and osteogenesis of mesenchymal stem cells. Birth Defects Res C Embryo Today. 2010;90(1):75-85.

34. Fu R, Liu Q, Song G, et al. Spreading area and shape regulate apoptosis and differentiation of osteoblasts. Biomed Mater. 2013;8(5): 055005 .

35. Mathieu PS, Loboa EG. Cytoskeletal and focal adhesion influences on mesenchymal stem cell shape, mechanical properties, and differentiation down osteogenic, adipogenic, and chondrogenic pathways. Tissue Eng Part B Rev. 2012;18(6):436-444.

36. Wang YK, Yu X, Cohen DM, et al. Bone morphogenetic protein2-induced signaling and osteogenesis is regulated by cell shape, RhoA/ROCK, and cytoskeletal tension. Stem Cells Dev. 2012; 21(7):1176-1186.

37. Frenkel V. Ultrasound mediated delivery of drugs and genes to solid tumors. Adv Drug Deliv Rev. 2008;60(10):1193-1208.

38. Chaudhary S, Smith CA, Del Pino P, et al. Elucidating the function of penetratin and a static magnetic field in cellular uptake of magnetic nanoparticles. Pharmaceuticals (Basel). 2013;6(2):204-222.

39. Komori T. Regulation of bone development and extracellular matrix protein genes by RUNX2. Cell Tissue Res. 2010;339(1):189-195.

40. Harada S, Rodan GA. Control of osteoblast function and regulation of bone mass. Nature. 2003;423(6937):349-355.

41. Lian JB, Stein GS. Development of the osteoblast phenotype: molecular mechanisms mediating osteoblast growth and differentiation. Iowa Orthop J. 1995;15:118-140.
42. Huang Y, Dai ZQ, Ling SK, Zhang HY, Wan YM, Li YH. Gravity, a regulation factor in the differentiation of rat bone marrow mesenchymal stem cells. J Biomed Sci. 2009;16:87.

43. Prodanov L, van Loon JJ, te Riet J, Jansen JA, Walboomers XF. Substrate nanotexture and hypergravity through centrifugation enhance initial osteoblastogenesis. Tissue Eng Part A. 2013;19(1-2):114-124.

44. Gebken J, Lüders B, Notbohm H, et al. Hypergravity stimulates collagen synthesis in human osteoblast-like cells: evidence for the involvement of p44/42 MAP-kinases (ERK 1/2). J Biochem. 1999;126(4):676-682.

45. Rawadi G, Vayssière B, Dunn F, Baron R, Roman-Roman S. BMP-2 controls alkaline phosphatase expression and osteoblast mineralization by a Wnt autocrine loop. J Bone Miner Res. 2003;18(10):1842-1853.

46. Baxter FR, Bowen CR, Turner IG, Dent AC. Electrically active bioceramics: a review of interfacial responses. Ann Biomed Eng. 2010; 38(6):2079-2092.

47. McBeath R, Pirone DM, Nelson CM, Bhadriraju K, Chen CS. Cell shape, cytoskeletal tension, and RhoA regulate stem cell lineage commitment. Dev Cell. 2004;6(4):483-495.

48. Shi Y, Li H, Zhang X, Fu Y, Huang Y, et al. Continuous cyclic mechanical tension inhibited Runx2 expression in mesenchymal stem cells through RhoA-ERK1/2 pathway. J Cell Physiol. 2011;2260(8): 2159-2169.

49. Nikukar H, Reid S, Tsimbouri PM, Riehle MO, Curtis AS, Dalby MJ. Osteogenesis of mesenchymal stem cells by nanoscale mechanotransduction. ACS Nano. 2013;7(3):2758-2767.

50. Ozdemir T, Xu LC, Siedlecki C, Brown JL. Substrate curvature sensing through myosin IIa upregulates early osteogenesis. Integr Biol (Camb). 2013;5(11):1407-1416.
International Journal of Nanomedicine

\section{Publish your work in this journal}

The International Journal of Nanomedicine is an international, peerreviewed journal focusing on the application of nanotechnology in diagnostics, therapeutics, and drug delivery systems throughout the biomedical field. This journal is indexed on PubMed Central, MedLine, CAS, SciSearch $®$, Current Contents $\AA /$ Clinical Medicine,

\section{Dovepress}

Journal Citation Reports/Science Edition, EMBase, Scopus and the Elsevier Bibliographic databases. The manuscript management system is completely online and includes a very quick and fair peer-review system, which is all easy to use. Visit http://www.dovepress.com/ testimonials.php to read real quotes from published authors. 